\title{
A reminiscence intervention case study: Enacting recovery principles in an inpatient psychiatric unit
}

\author{
Julaine Allan ${ }^{1 *}$ and Nicole Herridge ${ }^{2}$ \\ ${ }^{1}$ Senior Research Fellow, Lyndon Community, Australia \\ ${ }^{2}$ Social Worker, Team Leader Headspace, Orange, Australia
}

\begin{abstract}
Recovery principles and practice are being implemented in Australia. In long stay psychiatric hospital wards structured around staff routines and shifts, concern with risks and policy constraints, enacting recovery methods is challenging. During a placement at a regional psychiatric hospital in NSW, a social work student undertook a reminiscence intervention to influence the nurses' deficit-focussed view of the patients with severe and persistent mental illness that they cared for. Three examples of how the reminiscence process was used are described. The staff reported perceiving the people they cared for differently after hearing about aspects of their lives outside the hospital setting. Reminiscence interventions have the potential to be used as a tool in the recovery journey in mental health and within the hospital setting. The reminiscence project was a challenging student placement that provided valuable learning for the social work team.
\end{abstract}

\section{Introduction}

Australian mental health services are universally taking on recovery principles and practice as the most effective and appropriate way to deliver treatment and support to people with mental illnesses and their families and carers. While the recovery approach has contested definitions and meanings [1] it is mostly described as personcentered and directed; embedded in lived experience and narratives of service users experience [2]; and different to clinical recovery or the measureable absence of symptoms [3]. In long stay psychiatric hospital wards structured around staff routines and shifts, concern with risks and policy constraints, enacting recovery methods is challenging for all social workers including students.

Australian student social workers complete two 500 hour placements during their degree. The broad aim of these placements is to learn about the social work role and the ways theory is applied in practice [4]. Students rely on their supervisors to understand the practice arena sufficiently to support learning and reflection and challenge the student's thinking and values [5]. When the practice concepts and theory are new, student and supervisor have an opportunity to learn together. In the placement described here the social work team had been looking for a way to apply recovery principles. The student placement provided the ideal opportunity to try something new. The student task was to identify and implement a recovery oriented project with hospital patients and social workers. The project and placement was to conclude with a social work team evaluation about the perceived impact and sustainability of the project.

This paper describes the application of a reminiscence intervention that intended to explore the lives of the patients with severe and persistent mental illness and reconnect them and their families with lives outside the hospital and mental illness treatment. Following an explanation of reminiscence interventions, the context and method of the project is detailed and an example of the way it was implemented described. The social work team evaluation is outlined.

Reminiscence is the process of recalling memories of one's self in the past [6]. The therapeutic intent of reminiscence comes from Erikson's theory of psychosocial development where successfully completing each stage is necessary for a balanced life. While reminiscence is described as a universally occurring and natural process for integrating past experiences, especially conflicts, into current experience; it is thought to be valuable as a facilitated process that brings a balanced perspective to current circumstances [7]. Reminiscence interventions, which include biography, life review, life history, and life stories, aim to gather an account of a person's life and in doing so impact upon the individual's care [8]. The goals of reminiscence interventions are diverse and include preserving/uncovering identity, humanising beyond medical diagnoses and to inform individualised care [9].

Undertaking a review of life challenges and accomplishments suggests that reminiscence interventions will be most effective for older people. For example, within an older population with depression, reminiscence therapy has produced results comparable to cognitive behavioural therapy and antidepressant medications $[8,10]$. However reminiscence has been shown to not be restricted to old age but closely linked with the re-construction of self-schemas and having positive associations with life satisfaction and well-being for younger people as well $[11,12]$. Further, patients, family and staff have described reminiscence interventions as an enjoyable activity [9].

The re-constructive nature of positive reminiscence has prompted the use of reminiscence interventions in a variety of health settings with positive impacts on life-satisfaction and emotional well-being of participants, particularly older adults $[6,13]$. Given that hospitalisation poses a potential threat to psychological well-being and life satisfaction [14], ways of ameliorating those effects for people in hospital for years is needed.

Correspondence to: Julaine Allan, Senior Research Fellow, Lyndon Community, Australia, Tel: 02-63612300; E-mail: jallan@lyndon.org.au

Key words: recovery principles, recovery practice, reminiscence, hospital social work, student placement

Received: June 09, 2016; Accepted: June 30, 2016; Published: July 04, 2016 
However, there are questions about the appropriateness of reminiscence for people with mental illness. Some authors have argued that to achieve reduced symptoms and improved self-esteem, reminiscence requires the construction of a coherent and consensually valid personal narrative where one is a meaningful agent [15]. Other research suggests that the functions of reminiscence are significantly impaired in individuals suffering schizophrenia, who have greater difficulties with extracting meaning from their memories and making connections with self-identity $[16,17]$. Challenges in undertaking the process do not necessarily mean it is a bad idea. Rather, from a recovery perspective the meaning making is what is significant and relevant to the person reminiscing, not if it is coherent to practitioners.

It may be that the way reminiscence interventions were implemented in some studies was unsuitable for the participants. Willemse, et al. [18] studied the impact of a structured reminiscence program for older persons with a severe mental illness, the majority of whom resided in a psychiatric hospital. Topics focussed on simple positive memories, and the majority of participants completed the process and stated that they were satisfied with the program. Participants with a psychotic disorder showed a significant increase in depression symptoms yet this appeared to be mitigated by an improvement in life satisfaction [18].

The strength of reminiscence intervention evidence is limited by varied methods of implementations, a lack of standardised interventions and diversity in the populations it is applied [19]. However, with the majority of studies to date reporting positive outcomes, reminiscence interventions have potential to be one way of enacting recovery principles within the hospital setting.

\section{Context}

The project took place in a psychiatric hospital in NSW, Australia as part of a social work student placement. Social work staff at the hospital believed that patients in the long stay wards were viewed primarily in terms of their mental illness including seeing their life experiences, needs and wishes as only those that occurred in hospital and in relation to their interactions with health workers. This view was supported by the details of medications and professional opinions recorded in individual files over years that were often the only history of patient's lives. The files were clinically focused and did little in the way of recounting the uniqueness or personhood of the individual [21].

The social work student was asked to find or develop; and implement a reminiscence intervention that had the following aims;

- Construct positive descriptions of patient lives and experiences

- $\quad$ Provide a vehicle for building upon identity and personhood of patients

- Increase quality and quantity of communication and social connections with staff \& family

- $\quad$ Provide a way to record and store meaningful personal documents such as photos, certificates and letters

The social work team perceived that changing a dehumanised view of hospital residents was one way of implementing recovery principles in the inpatient setting. Using a reminiscence intervention to record an alternative life story of patients and sharing it with nursing staff was the chosen strategy to construct alternative narratives and challenge deficit focused language [22].

During the time of the intervention, late 2013, the ward accommodated 19 people, with a bed limit of 20. Ten females and 9 males were in residence with age ranging from $33 \mathrm{yrs}$ to $67 \mathrm{yrs}$. The average age was 54 years. The length of stay of residents at the psychiatric hospital ranged from $1 \mathrm{yr}$ to $39 \mathrm{yrs}$ with an average length of stay of 12 and a half years. The predominant diagnoses of the residents were schizophrenia and schizoaffective disorders.

A resource was needed to guide the reminiscence intervention and record the personal stories. A personal life history booklet developed by local mental health staff for patients experiencing dementia was reviewed by the social work team and suggestions were made for its revision. The revised workbook contained closed questions about what were broadly considered positive memories, such as special memories from childhood, special relationships and favourite family traditions. As one aim of the project was to strengthen familial communications, the booklet was developed to be completed with a loved one or close care staff, and included additional questions such as "family member's special memories of me" and specific strengths based questions such "what are your qualities?" [22].

\section{Implementation}

The social work team identified the annual family day as a good way to commence the project and involve family in providing information and stories for the reminiscence. Patients and nurses were informed about the project and that it would start on family day. On the annual family open day, residents were asked if they would like to participate. Booklets were distributed to the family members of those who wanted to complete the activity. Instructions were to focus on pleasant memories and to take as much time as needed. Twelve families were given a booklet and five were returned on the day, with four other families indicating their intention to complete and return the booklet. Feedback to social workers suggested that filling out the booklet was an enjoyable and important activity for family and residents.

One resident, Maree a 48 Aboriginal woman who had not had contact with her family for over 20 years was reunited with her younger sister, Tammie, and her nieces and nephews on the annual family day. The family used the booklet to guide the conversation over the course of the day. Tammie discussed Maree excelling in sports during her teens, stories from family holidays and personal strengths such as respect for elders, a caring and trusting nature.

Following the family day the student worked with Yvonne, a 32 year old woman diagnosed with treatment resistant schizophrenia. Yvonne's family had not started the booklet and so the student began working through this document with her several times over the course of a few weeks. The life history booklet served as a prompt as Yvonne would excitedly elaborate on her favourite childhood memories and the skills and abilities she saw in herself, such as being a loyal friend and caring person. Yvonne took the initiative of collecting photographs and sharing collected photographs and recalled associated stories about her family and herself, information that was written down as she spoke. Yvonne talked about how much she enjoyed sharing stories. With Yvonne's permission, the student contacted Yvonne's mother to obtain additional details of events Yvonne had recalled.

The final booklet was around seven pages, which consisted of a cover page with a picture of Yvonne that she chose and a background with her favourite colour. The booklet also contained photographs with captions, a short story detailing Yvonne's personal achievements, such as her studying and working in the hospitality industry and her more recent successes of increasing her physical activity and taking her 
medication regularly with the aim towards achieving her goal of moving back to Sydney and securing more independent accommodation.

The final booklet contained Yvonne's values and strengths, as well as a family tree with pictures. Once this was complete the student read the story to Yvonne and then gave her the booklet. Yvonne smiled and thanked the student for her story booklet.

The student assisted in completing a reminiscence booklet for another resident, Greg. He had been a resident of the ward for over a decade. As part of Greg's life story, the student interviewed the nurse unit manager (NUM) of the ward. The NUM described how hard Greg had worked on improving his mental health, how he was trustworthy and an all-round "good bloke". After reading him his life story including the NUM's interview, Greg smiled and said "that's lovely, what he [the NUM] said".

In another example, one person was frequently referred to in patient files as "intrusive" and "demanding". The social work student interviewed a nursing staff member about this particular resident using strengths orientated language "If ......... moved out of the ward, what would be most missed about them?" "What do you see as....... strengths?" "What is a story that demonstrates....... strengths/unique characteristics?" Following this interview the social work staff noted that the language used to describe patient behaviours made a marked move from deficit-focussed to a more strengths orientation. For example this resident was referred to as "being a good mother".

\section{Evaluation}

The four aims of the project - to construct positive descriptions of patient's lives, provide a tool for building upon patient identity, increase connections with staff and family and record personal documents were achieved during the student placement.

The feedback received from residents who participated in the reminiscence project was positive. Key aspects of the project that made it positive for the student were frequent consultation with patients and supporting their wishes in the way the booklet was developed. The student found that during times between consultations with the patients, some would spontaneously approach her to recount a memory about them, or thank her for recovering their photographs. As old photographs were uncovered, staff showed a keen interest which sparked positive interactions with residents. It appeared that the salient aspect of the intervention was the process of creating the booklet. The process included listening, respecting and developing a trusting relationship with the patient and involving their family where possible. Without these elements it would not be possible to achieve the goals of the project [23]. This also achieved the aim of having some record of the patient's life that included photos and stories from outside the hospital.

The social work team noted in social work team reflection that during the course of the student's placement, the reminiscence project appeared to have changed staff perceptions of patients in the ward. It was noted that nursing staff, which were previously observed to have their interactions with patients limited to medical and behavioural interventions were reviewing residents' photographs and life history booklets and asking questions of the residents. Social workers perceived these interactions as person-centered and strengths based rather than clinical interest in mental illness symptoms.

The social work reflection identified the student's participation was a key element of the project. The student had the time to identify the reminiscence resources, sit down with patients and families and work through the booklets, to search through old medical records for information and to spend time with staff collecting their stories of the people in the ward. The project provided learning opportunities for the student around ethical practice, recovery orientation and implementing new approaches within a multi-disciplinary team. The social workers also perceived the reminiscence activities would be sustainable because the process was developed, the tools were trialled and suitable and the impact had been tested.

While the project was new for the social work team as well as the student, the social work supervisor was able to support the student through critiquing the available tools of reminiscence and reflecting on and addressing the ethical dilemmas that arose. The key ethical dilemma is a critically important challenge to social work practice risk of harm from a social work led intervention. People's personal values frequently uphold the importance of family connections and nostalgia for past significant events [15]. Professional social work values recognise personal and cultural diversity upholding the right to choose change focussed interventions where ever possible. Personal trauma histories and family violence and abuse could be reasons for not undertaking reminiscence interventions but people should not be denied the opportunity because of fear of harming them. Somehow the reminiscence option needs to be offered and explained to people so they can choose for themselves.

\section{Conclusion}

Reminiscence is connected to the development of identity and has been linked with positive psychological functioning. Reminiscence interventions have yielded positive results, however much more research is needed to provide conclusive results and to provide practitioners with best practice guidelines. Social workers in psychiatric hospitals are critical elements in enacting recovery principles because of the profession's concern with family and context as important elements of a person's life. Typically task focussed psychiatric hospital social workers may have to make time to work differently if they want to use reminiscence in their work. As reminiscence interventions may have the potential to be used as a tool in the recovery journey in mental health, this is an area that warrants further investigation.

\section{References}

1. Slade M, Amering M, Oades L (2008) Recovery: An international perspective. Epidemiol Psichiatr Soc 17: 128-137. [Crossref]

2. Kogstad RE, Ekeland TJ, Hummelvoll JK (2011) In defence of a humanistic approach to mental health care: Recovery processes investigated with the help of clients' narratives on turning points and processes of gradual change. J Psychiatr Ment Health Nurs 18: 479-486. [Crossref]

3. Hyde B, Bowles W, Pawar M (2014) Challenges of recovery-oriented practice in inpatient mental health settings-the potential for social work leadership. Asia Pacific J Soc Work Dev 24: 1-2.

4. Scott V, Laragy C, Giles R, Bland R (2004) Practice standards in Australia: implications for social work education. Social Work Education: The Intern Journal 23: 613-624.

5. Wilson G, Walsh T, Kirby M (2008) Developing Practice learning: Student perspectives Social Work Education 27: 35-50.

6. Bluck S, Levine LJ (1998) Reminiscence as autobiographical memory: A catalyst for reminiscence theory development. Ageing and Society 18: 185-208.

7. Haight BK (2007) Transformational reminiscence: Life story work. New York, NY Springer Publishing Co.

8. Peng XD, Huang CO, Chen LJ, Lu Z (2009) Cognitive behavioural therapy and reminiscence techniques for the treatment of depression in the elderly: A systematic review. J Int Med Res 37: 975-982. [Crossref] 
9. McKeown J, Clarke A, Repper J (2006) Life story work in health and social care: Systematic literature review. $J A d v$ Nurs 55: 237-247. [Crossref]

10. Adamek ME, Slater GY (2008) Evidence-based interventions for cognitive and mental health issues. J Gerontol Soc Work 50: 151-189.

11. Bohlmeijer E, Roemer M, Cuijpers P, Smit F (2007) The effects of life-review on psychological well-being in older adults: a meta-analysis. Aging Ment Health 11: 291300. [Crossref]

12. Webster JD (1993) Construction and validation of the Reminiscence Functions Scale. $J$ Gerontol 48: 256-262. [Crossref]

13. Westerhof GJ, Bohlmeijer E, Webster JD (2010) Reminiscence and mental health: a review of recent progress in theory research and interventions. Aging and Society 30: 697-721.

14. Haight B, Michel Y, Hendrix S (1998) Life review: Preventing despair in newly relocated nursing home residents short- and long-term effects. Intern J Aging Human Develop 47: 119-142.

15. Lysaker PH, Ringer J, Maxwell C, McGuire A, Lecomte T (2010) Personal Narratives and recovery from schizophrenia. Schizophr Res 121: 271-276. [Crossref]
16. McLeod HJ, Wood N, Brewin CR (2006) Autobiographical memory deficits in schizophrenia. Cogn Emot 20: 536-547. [Crossref]

17. Raffard S, D'Argembeau A, Lardi C, Bayard S, Boulenger JP, et al. (2010) Narrative identity in schizophrenia. Conscious Cogn 19: 328-340. [Crossref]

18. Willemse BM, Depla M, Bohlmeijer ET (2009) A creative reminiscence program for older adults with severe mental disorders: Results of a pilot evaluation. Aging and Mental Health 13: 736-743.

19. Shilling SE (2014) Reminiscence and Structured Life Review-Treating Depression in Older Adults.

20. AASW: code of ethics ( $3^{\text {rd }}$ ed.) (2010) Australian Association of Social Workers, Barton, A.C.T.

21. Healy K (2005) Social Work Theories in Context, Creating Frameworks for Practice. Palgrave McMillian, UK.

22. Strengths Cards (2010) St Luke's Innovative Resources, Bendigo VIC.

23. Cummins LK, Sevel JA, Pedrick LE (2006) Social Work Skills Demonstrated ( $2^{\text {nd }}$ ed.) Pearson Education, Inc, USA.

Copyright: (2016 Allan J. This is an open-access article distributed under the terms of the Creative Commons Attribution License, which permits unrestricted use, distribution, and reproduction in any medium, provided the original author and source are credited. 